\title{
EDITORIAL
}

Volume 7 No. 3

\section{The consilience of learning design}

In October 2014, a fascinating Creative Commons paper, authored by academics Will J. Grant and Rod Lamberts, appeared in the Australian issue of The Conversation $<$ http://theconversation.com>. Its title was The 10 stuff-ups we all make when interpreting research. Although based in the reporting of Science, this is a paper we should all read both in terms of its value for our own writing and publication and in evaluating the research reporting of our students and our colleagues. The reported "stuff-ups" are:

1. Wait! That's just one study!

2. Significant doesn't mean important

3. And effect size doesn't mean useful

4. Are you judging the extremes by the majority?

5. Did you maybe even want to find that effect?

6. Were you tricked by sciencey snake oil?

7. Qualities aren't quantities and quantities aren't qualitites

8. Models by definition are not perfect representations of reality

9. Context matters

10. And just because it's peer reviewed that doesn't make it right.

In our experience and of interest to the Journal of Learning Design is that these criticisms are frequently accorded in a generic way to the scholarship of teaching, particularly in terms of the small scale of studies we typically report and the contention that they represent the exception rather than the rule. For example, many of our authors report on their own classes within their own disciplines or within one institution or with a single cohort of students.

To us, however, the authors of the papers we publish share profound concerns with teaching and learning which make who they are, where they are from and what they teach almost irrelevant. They make sense of the whole by focussing on their part of it. Not discounting the important signature pedagogies of discrete disciplines or underestimating the importance of context in educational research (Gibbs, 2010), what is featured in this journal is what might be referred to as consilience, that is, a building towards a metanarrative of learning design.

Consilience was first coined as a term in 1840 by William Whewell in The Philosophy of the Inductive Sciences. It was more recently formalised in 1998 by Edward O. Wilson in Consilience: The Unity of Knowledge. The latter title gives a clue to the meaning of consilience, that is, a "unity of knowledge" developed through the linking together of principles from different disciplines. While no single issue or annual volume of the Journal of Learning Design even 
pretends to develop a definitive or comprehensive theory, this is, in essence, the overarching goal of the journal over time. Its authors and editors, collaboratively and collectively, are building a unified theory of teaching and learning from different disciplines. Ziman (1969) publishing in the prestigious journal, Nature, argued - through somewhat fulsome metaphors - that:

Although the best and most famous discoveries seem to open whole new windows of the mind, a typical scientific paper has never pretended to be more than another little piece in a larger jigsaw - not significant in itself but as an element in a grander scheme. This technique of soliciting many modest contributions to the vast store of human knowledge, has been the secret of Western science since the seventeenth century, for it achieves a corporate, collective power that is far greater than any one individual can exert. Primary scientific papers are not meant to be final statements of indisputable truths; each is merely a tiny tentative step forward, through the jungles of ignorance. (p. 318)

This means that, as in this issue, while what you read might not have clear or unambiguous connections to a comprehensive theory, they nonetheless form part of it - building, telling the same story in different ways, and achieving similar outcomes in differing ways. A unity of knowledge does not mean a simple unilateral view or approach. Within the notional "stuff-up" of Context Matters, Grant and Lamberts (2014) argued that: Individual scientists - and scientific disciplines - might be great at providing advice from just one frame. But for any complex social, political or personal issue there are often multiple disciplines and multiple points of view to take into account (para. 33). What appears in this issue contributes to a consilience of learning design, different but logical equivalent experiences and observations achieved through differing means of measurement and seen through very different eyes. Narrower contextualised viewpoints are merely fractals of a larger kaleidoscope. Here, individual teachers or teaching teams provide the breadth and multiplicity we need to respond to complex issues.

On the surface, the articles in this issue have few shared characteristics. Your task as reader is to look beyond the context, that is, the what, when and where, and rather focus on the how and why. There is a loose connection here to the concept of learner engagement irrespective of who they are and to the critical processes of selection of technology or teaching method or of moderation and assessment. As you engage with the papers in this issue, you are asked to take on board the final advice from Grant and Lamberts (2014) that:

Just like in any other aspect of our lives, in the end, we have to make our own decisions. And sorry, appropriate use even of the world's best study does not relieve us of this wonderful and terrible responsibility.

There will always be ambiguities that we have to wade through. So like in any other human domain, do the best you can on your own; but if you get stuck, get some guidance directly from, or at least originally via, useful experts. 


\section{This issue}

Our first paper, by Doherty, then at the eLearning Pedagogical Support Unit, University of Hong Kong, discusses a pedagogical approach underlying the design and revision of a professional development course in eLearning, that is, an eLearning Certificate Course grounded in authentic practice. In this paper, Doherty systematically outlines many of the issues faced in many tertiary institutions and recommends paying greater attention to the affective domain, that is, concerning learners' beliefs, motivation and confidence. The paper also, importantly, takes account of the fact that many teachers and support staff in higher education have no formal qualifications in teaching. To counter this and to ensure their continued engagement in the course, Doherty's re-design was built on social constructivism and took advantage of the "proximity-to-practice" essential in professional learning. Confidence, relevance and motivation have been made central to the course revision.

The second paper, by Hickey from the QUT Business School, takes an intriguing theoretical look at the importance of learning philosophy in the selection of learning technologies. This paper, through addressing the fundamental question of "what is learning" critically connects Socratic, behaviourist and socio-constructivist views of learning to how we make use of technology to support teaching and learning to engage learners. This paper shares a key understanding with the previous paper (Doherty, this issue), that is, of the complex nature of learners particularly in regard to their experience and motivation. It shares the loose theme of engagement that runs through this issue.

In the third paper in this issue, Trevathan, Myers and Gray directly address student engagement. This paper empirically describes how a particular methodology, namely the Process Oriented Guided Inquiry Learning method or POGIL, has been adopted in a large Information Systems unit in an IT degree. The study described in this paper applied POGIL to the added challenge of engendering engagement in large classes in a lecture setting.

The fourth paper in this issue has been developed by a large team led by Trina Myers from James Cook University (Myers, Blackman, Gray, Anderson, Hay \& Lee) and funded by the Australian Council of Deans ICT (ACDICT) Learning and Teaching Academy (ALTA). It shares an interest in POGIL with the previous paper (Trevathan, Myers \& Gray, this issue) but in this instance has moved to an online learning environment. These authors, in differing combinations have contributed further on this topic through the pages of this journal (see, Myers, Monypenny \& Trevathan, 2012; Trevathan \& Myers, 2013). Perhaps their work considered as a combined body of knowledge - can be seen as working towards a consilience around this particular approach to teaching. But this paper goes further and, in better coming to terms with learner engagement, also investigates IF-AT or the Immediate Feedback Assessment Technique. Consilience runs between as well as within the issues of this Journal.

The fifth paper, by Adie from Queensland University of Technology, adds to the consilience of learning design which marks this issue. In this paper, an investigation is made of the moderation of assessment, that is, the processes of negotiation, clarification, and explanation within teaching teams to agree on student outcomes. Just as with the authors in the previous paper, this critical process has been moved online taking advantages of the concept of technological agency while maintaining the affordances of their offline processes. Adie here concludes that: "As technological communications continue to evolve, it is important that our conceptual frameworks also evolve to encompass rather than simply acknowledge the effect of the technology on these processes and the complex relationship of the technology in 
developing the culture and the practice" (p. 65). Also, in an inadvertent link to all other papers in this issue, Adie speaks of the "flow of relationships ... which make up the social and cultural context" (p. 63).

The final two papers in this issue report on practice from the perspective of the teachers/learning designers/authors. Neither is grounded in comprehensive research and might arguably fall under the criticism of Grant and Lamberts (2014) but each has an important contribution to make to how we teach and design learning experiences in response to contemporary challenges. That is, they add constructively to the consilience of learning design, emerging through this journal.

The first of these reports, the sixth paper in this issue, by Thomson, Bridgstock, and Willems from Queensland University of Technology, reports on the authors' experience with video resources within a Creative Industries Faculty. It offers a response to the challenge of engaging contemporary students and in arriving at the most effective media to convey particular messages. They conclude with four useful principles for planning education videos. These are: (i) Give context and align purpose; (ii) Tell (show) a story; (iii) Keep it as short as possible; and (iv) Present with authenticity. These principles are drawn logically from lived experience and grounded in an established research base.

In the second of this set, and the seventh and final paper of the issue, Cimadomo reports on the changes made within a degree in Architecture to align it to the European Higher Education Area (EHEA) framework. The overarching aim of this process returns us to the theme of engagement which has loosely connected the papers in this issue. It also aligns with the shift to online tools described by Myers, Blackman, Gray, Anderson, Hay \& Lee (this issue). Most importantly, it documents how one person has responded to a particularly disruptive challenge, here, the imposition of student-centered pedagogies and made a significant contribution to the consilience of learning and teaching.

This issue concludes Volume 7. We wish to sincerely thank the contributing authors and to the reviewers for the three issues in this volume and to the guest editors of the Special Issue on Science Education (Volume 7, Issue 2).

Postscript: In defence of these fine colleagues, we need to revisit the two commentaries reported in this editorial. The first cited was Grant and Lamberts (2014) whose \#10 "stuff-up" was: And just because it's peer reviewed that doesn't make it right; while the second cited, Ziman (1969) went on to equate review to censorship.... These are self-evident in their criticism of academic publication in general. To this, all we can say is, you have to trust someone some time. The Journal of Learning Design endeavours to make sure that personal experiences of broad instances of learning design do have a forum but that, rather than being censored, are selected on the basis of the rigour of their examination and their grounding in research or systematic observation. We would hope to not become a journal with a single voice, a monocular perspective or to offer a single template for successful learning design. We commend this issue to you.

\section{Margaret Lloyd}

Nan Bahr

Queensland University of Technology,

Australia 


\section{References}

\section{References}

Gibbs, G. (2010). The importance in understanding teaching and learning: reflections on thirtyfive years of pedagogic research. In Proceedings of the International Conference on the Scholarship of Teaching and Learning. Liverpool, UK. Retrieved from http://issotl10.indiana.edu/opening.html

Grant, W.J., \& Lamberts, R. (2014, October 3). The 10 stuff-ups we all make when interpreting research. The Conversation. Retrieved from http://bit.ly/1vf5DYJ

Myers, T., Monypenny, R., \& Trevathan, J. (2012). Overcoming the glassy-eyed nod: An application of process-oriented guided inquiry learning techniques in information technology. Journal of Learning Design, 5(1), 12-22.

Trevathan , J., \& Myers, T. (2013). Towards Online Delivery of Process-Oriented Guided Inquiry Learning Techniques in Information Technology Courses. Journal of Learning Design, 6(2), 111.

Ziman. J. M. (1969). Information, communication, knowledge. Nature, 224, 318-324. 